\title{
Research on the Relationship between Theoretical Economics and Applied Economics
}

\author{
Mingshan Cheng \\ Department of Applied Mathematics and Economics, Sichuan Vocational and Technical college, \\ Sichuan, China \\ Sino1980@163.com
}

Keywords: Relationship, Theoretical Economics, Applied Economics

\begin{abstract}
With the rapid development of China's current market economy, for more and more widespread use of economics, applied economics more and more experts and business managers attention. Most of the heavy presence of economic research practices, the problem of light theory, the upper surface of the favorable development of applied economics, but in the long run, the lack of economic development of the theory of good assistant, the development of applied economics will be limited. Theory of economics as applied economics group clumsy, summarizing all economic phenomena, is the relationship between theory and practice between the two. From the study of economics, the development process in the presence of the current problems, we analyzed the inseparable between economic theory and applied economics relations, proposals for the education and research work in the future economics.
\end{abstract}

\section{Introduction}

For a long time, in the characteristics of basic research and applied research, theoretical economics and applied economics knowledge or judgment on the domestic and foreign economists have similar views. For example, some domestic economists believe that, "In general, a higher level of abstraction theoretical economics, applied economics and abstract level is low. The actual operation of the practicality of theoretical economics economy is small, and applied economics greater practicality. "Western economists also believe that the basic sciences ignore the real social problems of application, and the application of science is given to these issues of great concern." Basic research during the process is not emphasized in the 'real world' application of policy and management issues, and applied researches are those most realistic questions to study."

Domestic scholars believe that the basic concepts of economic theory discussed economics, fundamental principles, and the general laws of economic operation and development, and provide a theoretical basis for the various economic disciplines. Marxist economic theory includes political economy, productivity economics. In Western economics, economic theory mainly refers to macroeconomics and microeconomics; Applied Economics mainly refers to the various departments with the regularity of the basic principles of economic theory study of the national economy, economic activity in various fields and economic relations, it includes industrial economics, economic management, regional economics, marketing and so on.

British and American scholars from the theoretical point tools define "economic theory." For example, the American economist Lloyd - Reynolds borrow the famous British economist Joan Robinson -formulation, that "economic theory" consists of three parts: microscopic tool mainly refers to microeconomics. The contents of mixing properties tools include price theory, general equilibrium theory, and so on. Macroscopic properties tools include monetary theory, economic growth theory, and so on. Reynolds believes that the above theory is the core of economic science system. As for the "Applied Economics", Reynolds believes many are related to the applied economics "is connected to the core", and accordingly established. He labor economics, money and banking and finance the establishment of an example to illustrate the problem. 
For theoretical economics and applied economics relations, the industry generally endorsed the "theory of economics is the foundation, is the concrete application of applied economics and practice," the thesis. But with the rapid development of China's economic system reform and the market economy, at this stage in our country this problem has been reintroduced to explore. Relationship between theoretical economics and applied economics and need further consideration, in-depth study, to meet the urgent needs of economic management and economic development, and guide the resolution of the various issues related to China's economic construction during the encounter.

\section{The Theoretical Economics}

Economics has been called the theory of political economy and the main contents are set forth some basic concepts and basic principles of economics and related exploration and development-related economic laws, economic theory is the basis for learning other subjects expanding economics class, among the general theory of economics. Economic theory is composed of two parts, one is the macro and the other is the micro economics. Usually in books or university campus are learning courses, such as history of Western economics, etc., are included within the scope of the theory of economics.

\section{The Applied Economics}

Applied Economics mainly for some of the financial and economic activity is mainly explore the relationship between law and development of various economic activities, but also for some economic activity a subject theory to analyze social formation. Institute of Applied Economic sectors involved will be relatively wide, will involve some basic productive sectors such as agriculture, industry and construction and other industries, there are many branches of applied economics, applied economics and therefore scope is very wide, while it can further supplemental content to economic theory, give full play to its role of usefulness.

\section{Research Status of the Applied Economics and the Theoretical Economics}

The one-sided tendency of publishing in the economics study. Currently publishing industry generally believe that, relative to the results of theoretical economics, applied economics more popular, so now it is easy to publish and distribute publications on applied economics or papers. In contrast, most of the press, and no theory of economics research has much interest, and often cold economic theory of contributing authors. Some publishers even some hard and fast rules and regulations promulgated out, if you want to require authors to publish academic monographs theory must be to submit the corresponding grant, and the amount of subsidy has a very high threshold, thus leading theory Economic research is difficult to leave out, resulting in a serious loss of this type of high-level academic work, which seriously affected the overall development economics.

The unappreciated theoretical academic research. In applied economics in China's economic academic research has been widely welcomed, thus leading to quick success by many scholars, economic interests and reputation were one-sided pursuit of, in particular, there are many in the research and practical solutions to economic problems talent, many scholars hesitate to use all means possible to join in the research teams in applied economics. Now theory of economics has become increasingly popular due to economic problems and practical application of economics a large concentration of young researchers, thus causing serious economic theory lack of talent.

\section{The Main Reason of One-Sided Tendency in Economics Research}

People from the objective of market regulation for the pursuit of social and economic benefits of the behavior, the theoretical basis of research is now slower and less effective income characteristics, and applied economics, by contrast, so whether school researchers or students to apply economics 
and social existence of great potential for economic efficiency have a full understanding, thus making a large concentration of applied economics of human, material and financial resources. School fund a lot of research in applied economics inclined, and the economic journal editorial staff and publishers also market effects and one-sided pursuit of economic interests, thus ignoring their own academic research should be required to assume a variety of responsibilities. In short, due to all causes of applied economics occupy a lot of resources and talent, eventually leading to a serious lack of motivation theory of economics development.

\section{The Relationship between Theoretical Economics and Applied Economics}

Application of the relationship between economics and economic theory from the essence, is the relationship between practice and theory, Marxist theoretical system tells us that practice is the source of the theory, and the theory and practice can guide. Now, however, in the eyes of many economic theory has only academic value, the actual value is truly applied economics, applied economics only be able to solve the economic problems out well, even if not required theoretical economics, only the need for applied economics can be well-managed enterprise, and can promote social progress and economic construction. However, the Marxist theory tells us that all things happen and the law of development, and its law irreplaceable objective meaning, only with basic theoretical support, can really solve the economic development issues that arise. Only by fully understanding the reason for this theory to be able to generate real economic problems to find out, and take effective measures to solve them, and ultimately can effectively avoid similar problems. Therefore, only the strong development of theoretical economics to be able to provide the motivation to applied economics, and the ability to theoretical basis and the value of various economic changes and phenomena to find out.

In fact, between the two concepts should be the relationship between theory and application is like a complementary relationship within the context of the theory and practice of philosophy, according to the study of philosophy, we understand that any study of theory is inseparable from the practice inspection, and only through the theoretical and practical examination of the theory is consistent with the law of development of the standard of value, both of which are indispensable relationship. After a lot of research data results show that only the economic theory as the theoretical basis, applied economics into practice, such Economics will become more valuable and meaning may be in the process of development of applied economics problems encountered in the theory of economics content will be reflected, and with the theory as a basis for economic activity will have a preliminary understanding of the theory, so that economic activity will be more easy to find problems, enabling better way to solve the problem for the future development of economic activities direction.

In short, if we really want to promote the development of applied economics play a role, we must to economic theory as a guide. The economic theory of development and progress can be effectively promote the emergence and development of the economy of things, therefore, from the essence of the existing one-sided heavy practice, thinking the light of the theory behind the cart before the horse belongs to a concept.

\section{Strategies for Solving Problems of Economic Abnormal Development}

Change the ideas and status of the academic. To the basis of balanced development economics and applied economics, the concept must be changed from the reverse of the current re-application, research situation in light of the theory. Through research fund to encourage and support policy for the study of economic theory to inject more momentum to provide a broader space for development and prospects theorists, prompting workers to more academic research into the theory of economics up .

Update economics education concept. From the school to the teachers, to the students, they must be a clear understanding on the concept of theoretical economics and applied economics to complementary and indispensable closely inseparable relationship. Rooted in the profound 
experience of applied economics theory, economic theory reflected in the use of the essential characteristics of applied economics. Learn firm ideas of basic economic theory. Only in this way, students can consciously learn basic economics, to strengthen the basic theory study and practice, and actively study to improve the theoretical level, completely changed their negative treatment, meet the test of attitude.

Update teaching methods and learning methods. Use the traditional chalk and talk teaching methods to lose, classroom theory of economics inevitably boring, boring. Theory cannot expect teaching through teacher lectures and students will be taught will be able to receive good teaching. In the process of teaching economic theory, should allow students to do more reading, more thinking and more exchanges. At the same time, students should be encouraged to write, whether it's learning experience, insights, or even comment article, should encourage students to creation. Teachers should play a guiding role in the students' self-learning. Guide students to balance theory time and energy on studying economics and applied economics between learning, to achieve the purpose of comprehensive development. Innovative learning methods to promote both economic theory student learning, and students will be able to learn the theory into practice, analyze and solve problems provide an opportunity to exercise.

Combine theory and practice. Emphasizing the importance of the basic theory of teaching, and not to the basic theory of education and practice of applied economics education separated. The so-called basic theory is by no means completely divorced from reality pure theory, but actually closely linked with economic and social theory inseparable. Do something with what they have learned, you cannot learn useless. As training methods is not conducive to the growth and development of talent. Economic theory must be able to serve in practice have existence value. By combining practical learning theory, Information theory to practice, in order to have a more profound understanding of the theory, practice a higher level of understanding. This is an effective way to improve the students to use the knowledge to analyze the issues, problem-solving abilities.

\section{Conclusion}

The theory is based on practice, practice is the Security Theory. Theoretical Economics study may lay a solid foundation for the development of applied economics, there is no thing as theoretical basis for many practical applications are out of the question, in today's market environment, we must master both the relationship between the changing way of thinking past mistakes, so that the content can contain both into economic activity were to go.

\section{References}

[1] Q.H.Ping, Research on the theory of economics, J. Economic Review. 2 (2013) 146-147.

[2] H.X.Zeng, Highlight the "political economy" dominant position in theoretical economics discipline construction, J. Contemporary Economic Research. 18(2012) 55-57.

[3] J.H.Xue, Economic Relations and Integration of the main branch of the theory of sustainable development, J. Shandong University of Finance, 32(2012) 189-190.

[4] Y.J.Qi, Analysis on theory economics and applied economics, J, Jianghan forum, 4(2011) 38-40.

[5] Y.M.Tian, The rise of the current set of disciplinary problems and law economics, J. Teaching and Research, 9(2013) 142-150. 